\title{
Transatlantica
}

Revue d'études américaines. American Studies Journal

\section{Gone With the Wind, 80 ans d'images. Entretien avec Pierre Berthomieu}

Pierre Berthomieu, Emmeline Gros et Marie-Pierre Burquier

\section{(2) OpenEdition}

1 Journals

\section{Édition électronique}

URL : https://journals.openedition.org/transatlantica/14288

DOI : 10.4000/transatlantica. 14288

ISSN : 1765-2766

Éditeur

Association française d'Etudes Américaines (AFEA)

\section{Référence électronique}

Pierre Berthomieu, Emmeline Gros et Marie-Pierre Burquier, «Gone With the Wind, 80 ans d'images. Entretien avec Pierre Berthomieu », Transatlantica [En ligne], 1 | 2019, mis en ligne le 01 juillet 2020, consulté le 01 février 2023. URL : http://journals.openedition.org/transatlantica/14288 ; DOI : https:// doi.org/10.4000/transatlantica. 14288

\section{Ce document a été généré automatiquement le 1 février 2023}

Creative Commons - Attribution - Pas d'Utilisation Commerciale - Pas de Modification 4.0 International - CC BY-NC-ND 4.0

https://creativecommons.org/licenses/by-nc-nd/4.0/ 


\title{
Gone With the Wind, 80 ans d'images. Entretien avec Pierre Berthomieu
}

\author{
Pierre Berthomieu, Emmeline Gros et Marie-Pierre Burquier
}

Ce média ne peut être affiché ici. Veuillez vous reporter à l'édition en ligne http:// journals.openedition.org/transatlantica/14288

\section{RÉSUMÉS}

Dans son entretien avec Denis Peyrat, directeur artistique de Gaumont, un journaliste en vint à la conclusion que "l'affiche de film n'obéit à aucune recette miracle ». Pourtant, à considérer les nombreuses affiches du film Autant en emporte le vent ou le film lui-même - qui a traversé les années sans jamais faire l'objet d'un remake -, on peut légitimement se demander s'il n'y a pas des ingrédients secrets qui en expliqueraient la longévité. Ce sont là certaines des questions abordées dans cet entretien avec Pierre Berthomieu, chercheur en études cinématographiques à l'Université de Paris, auteur notamment de Hollywood, le temps des géants (Pertuis, Rouge profond, coll. « Raccords », 2009).

In an interview with Gaumont's artistic director Denis Peyrat, a journalist came to the conclusion that "film posters do not obey any miracle recipe." However, when we consider the many posters of Gone With the Wind or when we talk about the film itself-a film that has survived the years and has never been the object of any remake-we can legitimately wonder if there are not any secret ingredients that would actually account for its longevity. These are some of the questions addressed in this interview with film scholar Pierre Berthomieu (Université de Paris), author of Hollywood, le temps des géants (Pertuis, Rouge profond, coll. "Raccords," 2009). 
INDEX

Mots-clés : Mitchell (Margaret), Autant en emporte le vent, plasticité, affiches, posters, longévité, cinéma hollywoodien, Leigh (Vivien), Gable (Clark), Berthomieu (Pierre)

Keywords : Mitchell (Margaret), Gone with the Wind, plasticity, posters, longevity, Hollywood cinema, Leigh (Vivien), Clark Gable, Berthomieu (Pierre)

\section{AUTEURS}

\section{PIERRE BERTHOMIEU}

CERILAC, Université de Paris

\section{EMMELINE GROS}

BABEL, Université de Toulon

\section{MARIE-PIERRE BURQUIER}

LARCA, Université de Paris 